\title{
Industrial Gold Brazing Alloys
}

\section{THEIR PRESENT AND FUTURE USEFULNESS}

\section{H. Sloboda}

Johnson Matthey \& Co Limited, London

More sophisticated brazing methods as well as the advent of new structural materials have posed difficult metal joining problems in the electronics, nuclear power, and aerospace industries. Certain of these, particularly in more critical applications, have been successfully solved by the use of gold-based brazing alloys, and this article reviews the present importance and potential scope of such alloys.

Until recently gold-bearing brazing alloys have been used almost exclusively in the jewellery trade. Many alloys of this kind, commonly known as carat gold solders, have been developed over the years not on the grounds of technical necessity but mainly to provide the goldsmith with a wide range of lowmelting solders matching the gold content and colour of a large variety of carat golds from which jewellery articles are fabricated. Their usefulness is therefore limited; in general engineering applications they have little to offer that cannot be found in much less expensive silver solders and base metal. brazing alloys.

Fig. 1 In the assembly of this Rolls-Royec RB211 turbojet engine a gold-based brazing alloy is being employed because it has excellent high temperature properties and produces joints that meet all the requirements of aerodynamie gas flow. This is important in reducing fuel consumption as well as smoke and noise levels
This review is concerned with entirely different materials developed in recent years in response to a demand created by new applications in the electronic, nuclear power, aero-engine, and spacecraft industries. New metal joining problems were posed by the more widespread use of sophisticated brazing methods and

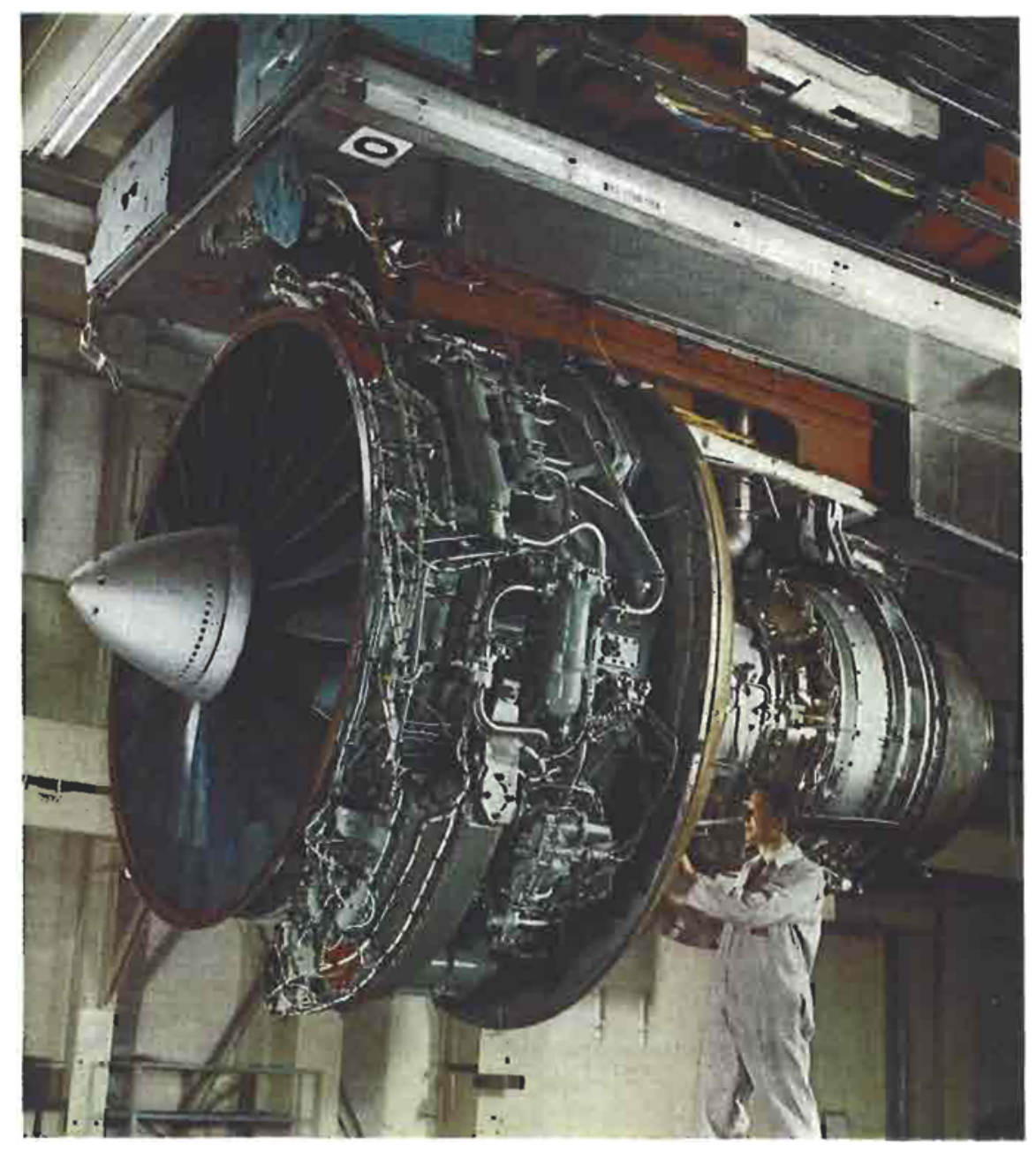


Table I

Industrial Gold Brazing Alloys

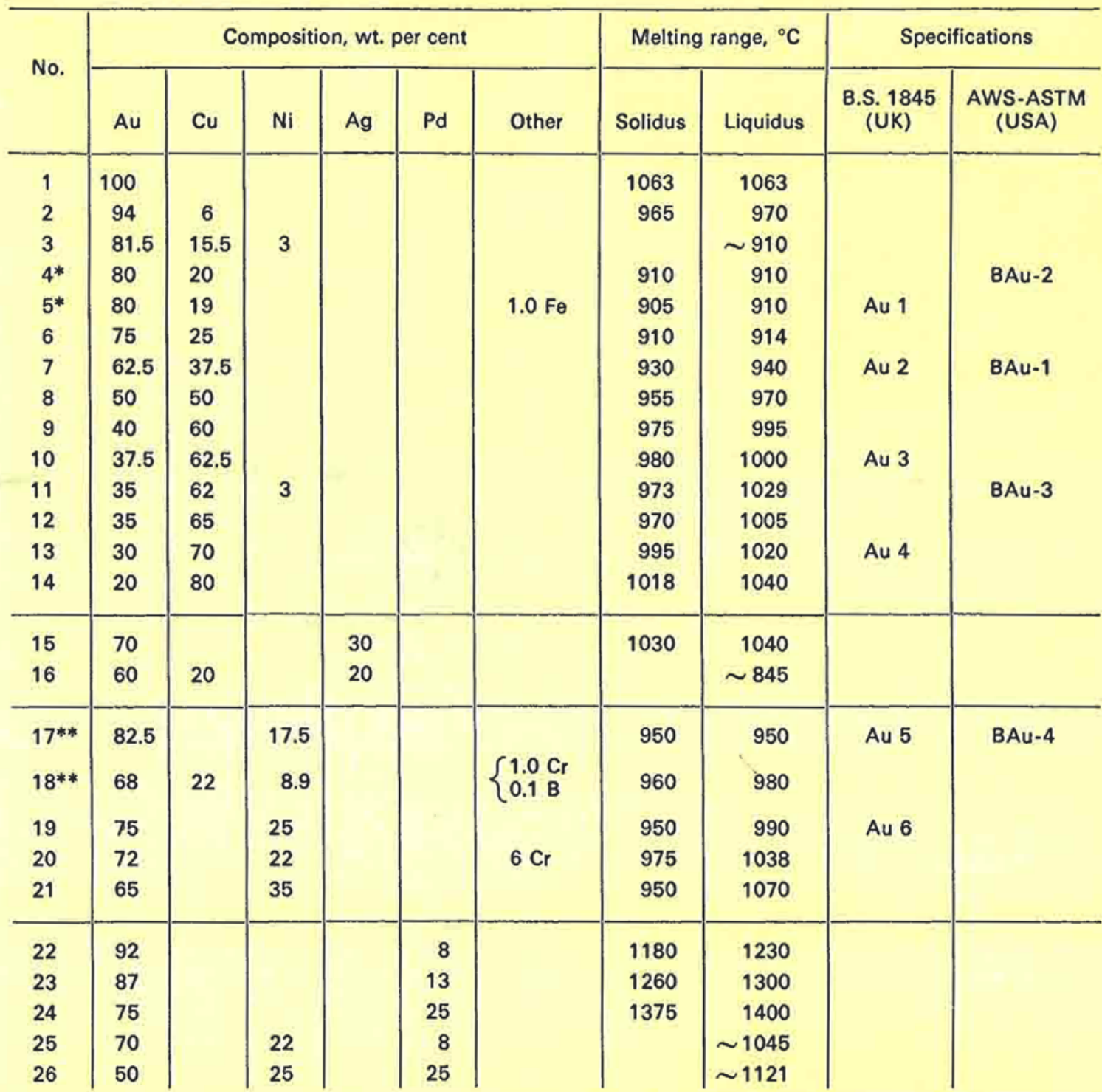

- Alloys Nos 4 and 5 are equivalent. A small quantity of iron is added to alloy No. 5 to retard the ordering transformation which takes place in the $80 \mathrm{Au}-20 \mathrm{Cu}$ alloy and which is accompanied by volume changes that cause difficulties in the fabrication of this material and may affect the properties of joints it produces (See British Patent Specification No. 681484).

*Alloy No. 18 is a recently developed, less expensive equivalent of alloy No. 17 with comparable wetting and free-flowing properties and high-temperature strength and oxidation resistance (British Patent Application No. 39805/68).

by the appearance of new structural materials whose improved mechanical properties and resistance to various environmental influences had to be matched by suitable joining materials. Solutions to some of these problems were found in specially designed base metal brazing alloys; in many critical applications, however, designers and metal fabrication engineers were forced to take recourse to alloys based on noble metals, among which gold brazing alloys occupy an important place. Commercially available brazing alloys in which gold is the major constituent are listed in Table $\mathrm{I}$, in which data on their composition and melting ranges are given. For the sake of completeness the table also lists pure gold which is sometimes used for low-temperature brazing of diffusion seals and for joining tungsten.

\section{Gold-Copper Alloys}

In formulating alloys listed under Nos 2 to 14, use was made of the rather unusual character of the goldcopper system. The equilibrium diagram of this system, reproduced in Fig. 2, shows that, although it 


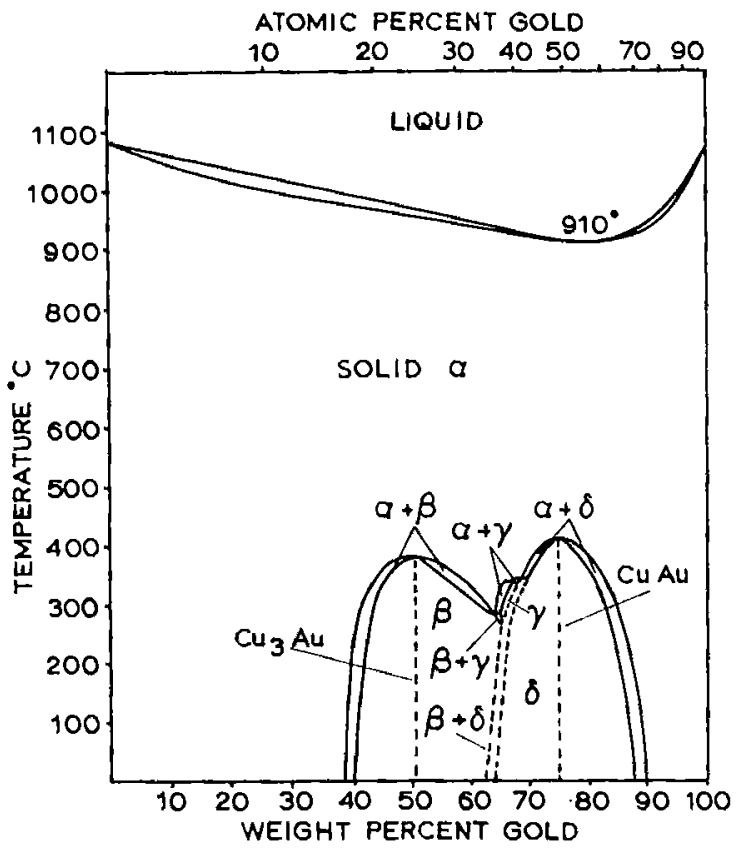

Fig. 2 The constitutional diagram of the gold-copper system. It will be seen that all alloys in the system have narrow melting ranges and are therefore potentially useful brazing materials

forms a continuous series of solid solutions, the liquidus and solidus temperatures of gold-copper alloys do not follow the additivity law. On the contrary, the melting point of each of these metals is reduced by the addition of the other. Moreover, the liquidus and solidus curves converge near the 80 per cent gold-20 per cent copper composition, which means that this single-phase binary alloy has no melting range. This property is often important from the brazing point of view because it is usually associated with high fluidity and ability to fill narrow joint gaps and to form small radius fillets. Other useful properties of gold-copper brazing alloys include the following:

(i) Ability to wet copper, nickel, iron, cobalt, molybdenum, tantalum, niobium, tungsten, and their alloys.

(ii) Ability to produce ductile joints without excessive inter-alloying. The latter factor is important in cases when excessive erosion of the work piece by molten brazing alloy could affect the dimensional accuracy of brazed parts or unduly weaken thin-walled structures.

Fig. 3 A cut-away view of an English Electric Valve Co magnetron. Its assembly involves a large number of gequential brazing operations, the first joint being made with pure platinum and the last with a tin-lead solder. The intermediate stages are carried out with gold-copper, gold-silver, and gold-copper-silver brazing alloys (iii) Freedom from volatiles and from constituents that form refractory oxides. The former is important when brazing is used to fabricate parts that operate in vacuum at elevated temperatures; freedom from elements that form refractory oxides makes for easy brazing without a flux in reducing and neutral atmospheres or in vacuum.

(iv) Exceptional resistance to corrosion, especially in the case of gold-rich alloys.

(v) Ability to be produced in wrought forms such as foil, strip, and wire. This is an important consideration in furnace trazing applications

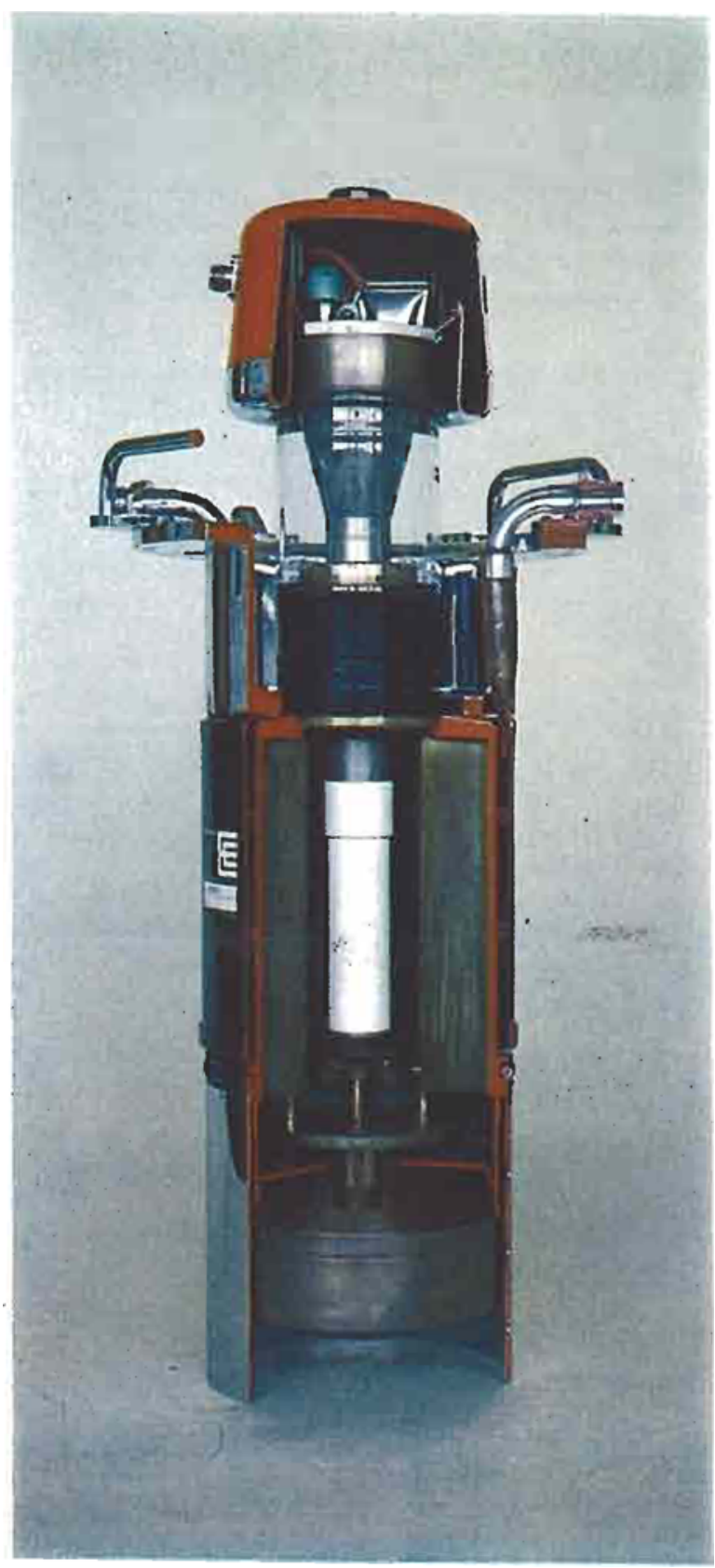


in which the brazing alloy must be preplaced in or near the joint area before brazing; shims and wire preforms often provide the most convenient means of doing it.

The largest consumer of gold-copper brazing alloys is the electronic industry where they are widely used in the fabrication of wave guides, electron tubes, valves, radar equipment, and vacuum devices. The reasons why these and other noble metal brazing alloys are especially useful in these applications can be best illustrated by reference to joining problems encountered in the manufacture of magnetrons (1).

The cavity magnetron (see Fig. 3 ) is a thermionic valve for generating microwaves. It is claimed to be one of the most complex mass-produced brazed assemblies. It comprises a large number of parts made of such diverse materials as copper, nickel, molybdenum, tungsten, brass, Monel, and a nickelcobalt-iron alloy. Its design and fabrication creates special problems because of the need for high precision, close proximity of joints to one another, difficulty of bonding some of the materials, high degree of vacuum in which the valve operates, intense localised temperatures in operation and long life expected of this type of valve.

The assembly of this device involves about a dozen brazing and soldering operations. These cannot be carried out simultaneously so that it is necessary to apply the so-called step-by-step brazing technique. In this technique each successive joint is made with a brazing alloy that has a melting point lower than that of the alloy used in the preceding operation; in this way the danger of the previously made joints being damaged by heat at any given stage is eliminated.

In this particular case the first joint (between the final turn of a coiled thoriated-tungsten heater and a molybdenum support) is made with pure platinum melting at $1770^{\circ} \mathrm{C}$ and the last (between copper cooling fins, nickel-plated mounting plate and silverplated output assembly) with a tin-lead solder melting at $199^{\circ} \mathrm{C}$. Brazing operations in the intermediate temperature range $\left(850\right.$ to $\left.1400^{\circ} \mathrm{C}\right)$ can be performed with any of the brazing alloys listed in Table $\mathrm{I}$, though (as already stated) gold-copper, gold-silver, and gold-copper-silver alloys are most often used in applications of this kind. Which alloy is used in a

Fig. 4 The constitutional diagram of the gold-nickel system on which oxidation-resistant brazing alloys are based. Alloys near the 80 gold-20 nickel composition are mostly used in brazing applications because they have narrow melting ranges and therefore good flowing characteristics
Table II

Typical Values of Mechanical and Physical Properties of Two Gold-Copper Brazing Alloys

\begin{tabular}{l|c|c}
\hline \multirow{2}{*}{ Property } & \multicolumn{2}{|c}{ Alloy composition } \\
\cline { 2 - 3 } & $80 \mathrm{Au}-$ & $62.5 \mathrm{Au}-$ \\
& $20 \mathrm{Cu}$ & $37.5 \mathrm{Cu}$ \\
\hline Melting range, ${ }^{\circ} \mathrm{C}$ & 910 & $930-940$ \\
U.T.S., tons/sq. inch & 30 & 27 \\
Elongation, per cent & 17 & 38 \\
Hardness (D.P.N.) & 250 & 112 \\
Electrical resistivity, & 14.2 & 13.9 \\
microhm-cm & 17.25 & 15.2 \\
Density & &
\end{tabular}

given case depends on the specific requirements relating to its melting point and other pertinent properties. A general idea about some room temperature characteristics of these materials can be gained from data cited for two gold-copper alloys in Reference 2 and reproduced in Table II.

\section{Gold-Nickel Alloys}

The next important group of gold brazing alloys is based on the gold-nickel system which, as shown in Fig. 4, is metallurgically analogous to the goldcopper system.

The number of binary gold-nickel alloys that are potentially useful as brazing media is relatively small and limited to alloys near the $82.5 \mathrm{Au}-17.5 \mathrm{Ni}$ composition which, like its counterpart in the goldcopper system, is distinguished by having a single

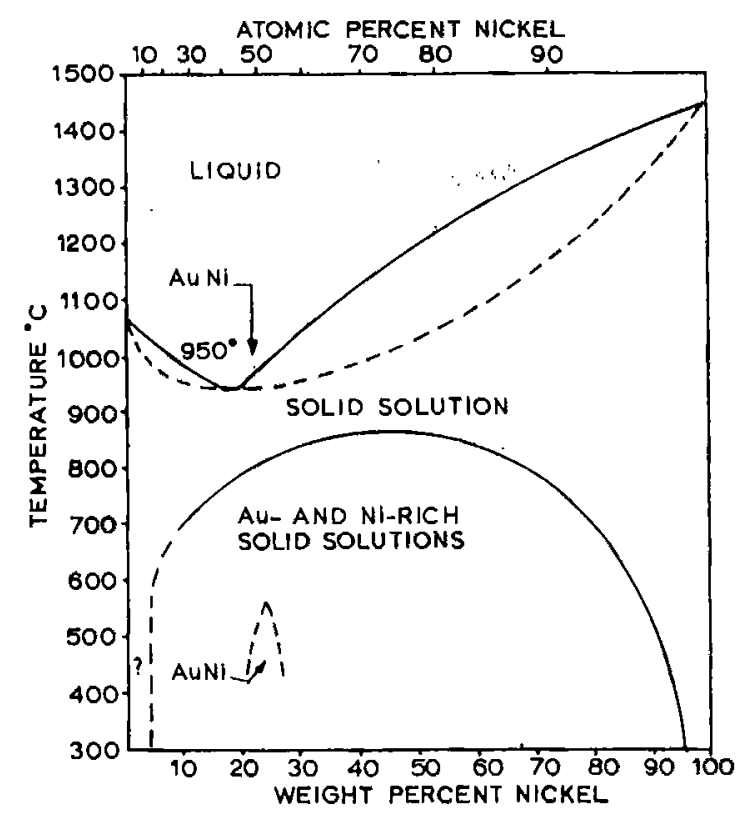


Table III

Comparative Data on the Corrosion and Oxidation Resistance of Gold-Nickel and Gold-Copper Brazing Alloys (3)

\begin{tabular}{|c|c|c|}
\hline \multirow{2}{*}{ Test conditions* } & \multicolumn{2}{|c|}{ Degree of damage } \\
\hline & $82.5 \mathrm{Au}-17.5 \mathrm{Ni}$ alloy & $80 \mathrm{Au}-20 \mathrm{Cu}$ alloy \\
\hline 100 hours in a $\mathrm{NaF}-\mathrm{ZrF}_{4}-\mathrm{UF}_{4}$ mixture at $815^{\circ} \mathrm{C}$ & Braze fillet unaffected & Braze fillet unaffected \\
\hline 100 hours in $\mathrm{NaOH}$ at $815^{\circ} \mathrm{C}$ & $\begin{array}{l}\text { Braze fillet attacked to a } \\
\text { depth of } 0.001 \text { inch }\end{array}$ & $\begin{array}{l}\text { Braze fillet attacked to a } \\
\text { depth of } 0.003 \text { inch }\end{array}$ \\
\hline 100 hours in $\mathrm{NaOH}$ at $593^{\circ} \mathrm{C}$ & No attack & No attack \\
\hline $\begin{array}{l}500 \text { hours at } 815^{\circ} \mathrm{C} \text { : } \\
\text { in static air } \\
\text { with } 220 \text { cools to room temperature }\end{array}$ & $\begin{array}{l}\text { Less than } 0.001 \text { inch attacked } \\
0.001 \text { inch attacked }\end{array}$ & $\begin{array}{l}\text { Complete oxidation } \\
\text { Complete oxidation }\end{array}$ \\
\hline \multicolumn{3}{|l|}{ In static air at $815^{\circ} \mathrm{C}$ for: } \\
\hline 200 hours & Less than 0.001 inch attacked & $0.002-0.005$ inch attacked \\
\hline 500 hours & Less than 0.001 inch attacked & Complete oxidation \\
\hline 1,300 hours & 0.001 inch attacked & - \\
\hline \multicolumn{3}{|l|}{ In static air at $926^{\circ} \mathrm{C}$ for: } \\
\hline 200 hours & $0.002-0.005$ inch attacked & Complete oxidation \\
\hline 500 hours & $0.002-0.005$ inch attacked & Complete oxidation \\
\hline
\end{tabular}

melting point. No gold-nickel alloys containing more than 35 per cent nickel are at present used because they have relatively inferior joint filling properties due to their wide melting ranges and high viscosity.

Brazing alloys based on the gold-nickel system have all the useful properties of gold-copper alloys. Where they score heavily over the latter materials is in their high-temperature strength and their resistance to oxidation at elevated temperatures. These differences are clearly illustrated by data reproduced from Hoffman and his co-workers (3) in Table III which, incidentally, show also that both gold-copper and gold-nickel alloys are very resistant to corrosion by molten fluoride mixtures.

Additional information on the oxidation resistance of joints brazed with a gold-nickel alloy is given in Table IV, while selected data, all from Chang (4), on certain mechanical properties, determined at both room and elevated temperatures of joints brazed with this alloy are reproduced in Tables V and VI.

Table IV

The Effect of Oxidation at $815^{\circ} \mathrm{C}$ on Room-temperature Tensile Properties of Joints Brazed with 82.5 Au-17.5 Ni Alloy in Steel AISI 347 ("Zero" joint clearance) (4)

\begin{tabular}{c|c|c|c|c}
\hline $\begin{array}{c}\text { Oxidation } \\
\text { time } \\
\text { weeks }\end{array}$ & $\begin{array}{c}\text { U.T.S. } \\
\text { tons/sq. inch }\end{array}$ & $\begin{array}{c}\text { Elongation } \\
\text { per cent }\end{array}$ & $\begin{array}{c}\text { Reduction } \\
\text { in area } \\
\text { per cent }\end{array}$ & $\begin{array}{c}\text { Location } \\
\text { of } \\
\text { failure }\end{array}$ \\
\hline 0 & 39.3 & 50 & 63 & Steel \\
1 & 42.0 & 52 & 64 & Steel \\
2 & 41.0 & 57 & 56 & Steel \\
8 & 41.0 & 51 & 57 & 31 \\
Steel & 39 & 30.5 & & Joint and steel
\end{tabular}


The reader may be puzzled by the fact that a figure of 39.3 tons $/ \mathrm{in}^{2}$ is cited in Table IV for room temperature strength (U.T.S.) of joints made with the $80 \mathrm{Au}-20 \mathrm{Cu}$ alloy in one grade of steel, while a figure of 85 tons/in* was recorded for the U.T.S. of similar joints made in a different steel. This is because brazed joint properties depend not only on the inherent strength of brazing alloys but also on the composition and properties of the materials brazed, on the joint design, and on brazing conditions (5). In this connection it should also be borne in mind that mechanical properties of brazed joints working at elevated temperatures may undergo substantial changes due to structural transformations and diffusion phenomena. The magnitude of this effect varies from case to case; in certain circumstances a complete loss of adhesion may occur (6).

High-temperature properties of gold-nickel alloys can be modified by the introduction of alloying elements. For instance, chromium added to these alloys increases their oxidation resistance (at the expense of their free-flowing characteristics) and confers on them the ability to wet graphite. Alloying can be used also to reduce the noble metal content (and therefore the intrinsic cost) of materials of this kind without losing any of their useful properties; this, incidentally, was the reason for developing the alloy listed in Table I as No, 18.

This material (an Au-Cu-Ni-Cr-B alloy) was developed in the Johnson Matthey Research Laboratories (7) to provide a less expensive equivalent of the standard $82.5 \mathrm{Au}-17.5 \mathrm{Ni}$ alloy used in relatively large quantities in the aircraft industry, which is the largest consumer of heat-resistant brazing alloys. The reasons for which gold-nickel alloys with their exceptional properties have been found indispensable in this field are again best illustrated by reference to a specific application.

The case in question was the fabrication of a modern aero-engine of the type shown in Fig. 1. One of its components in which brazing had to be used as the joining method is the H.P. compressor module. The brazing alloy used in this case had to possess the following properties.

(i) Ability to wet, and to produce sound joints on, "Jethete" (a heat-resistant steel containing up to 0.45 per cent $C, 0.5-0.9$ per cent $\mathrm{Mn}$, 11-12.5 per cent $\mathrm{Cr}, 2-3$ per cent $\mathrm{Ni}, 0.25-0.4$ per cent $V$ and 1.5-2.0 per cent $\mathrm{Mo}$ ).

(ii) A melting point below $1000^{\circ} \mathrm{C}$. ("Jethete" parts were brazed in a heat-treated condition; heating them above $1000^{\circ} \mathrm{C}$ during brazing would have destroyed the beneficial effects of the heat treatment).

(iii) Freedom from volatile constituents, to permit brazing to be carried out in vacuum.
Table V

The Effect of Temperature on the Tensile Properties of Joints Brazed with 82.5 Au17.5 Ni Alloy in Steel AISI 410. ("Zero" joint clearance; tests carried out on specimens in the as-brazed condition) (4)

\begin{tabular}{c|c|c}
\hline $\begin{array}{c}\text { Test temperature } \\
{ }^{\circ} \mathrm{C}\end{array}$ & $\begin{array}{c}\text { U.T.S. } \\
\text { tons/sq. inch }\end{array}$ & $\begin{array}{c}\text { Elongation } \\
\text { per cent }\end{array}$ \\
\hline 20 & 85.0 & 8.0 \\
260 & 85.0 & 6.0 \\
540 & 47.0 & 2.0 \\
650 & 18.0 & 10.0
\end{tabular}

(iv) Freedom from a tendency to erode the parent metal due to excessive interalloying. Joint fillets and the adjacent areas, which could not be dressed after brazing, had to be perfectly smooth because of aerodynamic gas flow considerations; this factor is important from the point of view of reducing the fuel consumption, and smoke and noise levels.

(v) High strength and oxidation resistance at temperatures of up to $500^{\circ} \mathrm{C}$

(vi) Ability to be produced in the form of powder, wire, strip, and foil for ease of preplacement. The only materials that could satisfy all the above requirements were the $\mathrm{Au}-\mathrm{Ni}$ and $\mathrm{Au}-\mathrm{Cu}-\mathrm{Ni}-\mathrm{Cr}-\mathrm{B}$ alloys.

Another interesting application of brazing with the 82.5 Au-17.5 Ni alloy is the fabrication of the lunar

Table VI

The Results of Charpy V-notch Impact

Tests on Specimens Brazed with the 82.5 Au-17.5 Ni Alloy (4)

\begin{tabular}{l|c|c|c}
\hline $\begin{array}{c}\text { Parent } \\
\text { metal }\end{array}$ & $\begin{array}{c}\text { Joint } \\
\text { clearance* }\end{array}$ & $\begin{array}{c}\text { Test } \\
\text { temperature } \\
{ }^{\circ} \mathrm{C}\end{array}$ & $\begin{array}{c}\text { Impact } \\
\text { strength, } \\
\mathrm{ft} \mathrm{Ib}\end{array}$ \\
\hline & "Zero" & 20 & 48 \\
"Zero" & 650 & 62 \\
AlSI 347 & 0.004 inch & 20 & 32 \\
& 0.004 inch & 650 & 45 \\
\hline Steel & "Zero" & 20 & 7 \\
AlSI 410 & "Zero" & 650 & 45 \\
(tempered & 0.004 inch & 20 & 45 \\
after & 0.004 inch & 650 & 75 \\
brazing) & 0.05
\end{tabular}

- Joint clearances cited in Tables II to IV are the clearances in the test-pieces as assembled for brazing; the actual braze thickness was approximately 0.002 inch larger. 
module of the Apollo spacecraft system (8). The propulsion and reaction control systems in this vehicle comprise 1046 joints in stainless steel tubing (3/16 to 2 in diameter, 0.016 to 0.057 in wall thickness) carrying fuel, oxidiser $\left(\mathrm{N}_{2} \mathrm{O}_{4}\right)$ and helium at pressures of up to $3000 \mathrm{psi}$. The gold-nickel alloy is used because of its resistance to $\mathrm{N}_{2} \mathrm{O}_{4}$; the brazing is done with a portable clamp-on induction coil under an inert gas shield.

The same alloy is one of three filler materials used in the brazing of the thrust chamber of the F-l engine powering the first-stage Saturn $V$ launch vehicle of the Apollo spacecraft system (9). Each thrust chamber, which must be fabricated to exceptionally high reliability standards, has 178 primary tubes and 356 secondary tubes and is constructed mainly of a high-temperature nickel alloy (Inconel X-750). The joints are made by a three-step furnace brazing process.

When complete freedom from oxidation is required in addition to all the useful characteristics of gold-nickel alloys, gold-palladium alloys can be used. These materials, some of which have relatively high melting points (up to $1400^{\circ} \mathrm{C}$ ), and gold-palladiumnickel alloys are often found useful in the first (i.e., high-temperature) stages of step-by-step brazing.

Detailed published information on the performance of joints made with gold brazing alloys in various structural materials for service in a wide range of working media and under diverse conditions of stress and temperature is unfortunately scarce. Nevertheless, the few applications described in this article show quite clearly the importance, the present scope and the potential future uses of materials of this kind.

\section{References}

1 D. Fishlock, "Precious Metal Brazing Makes Better Magnetrons", Metalworking Prod., 1961, 105, 49-53

2 Anon., "Special Purpose Brazing Alloys", Metallurgia, $1961,63,(3), 142-144$

3 E. E. Hoffman, P. Patriarca, C. F. Leitten and G. M. Slaughter, "An Evaluation of the Corrosion and Oxidation Resistance of High Temperature Brazing Alloys", ORNL Rept. UC-25, 1956

4 W. H. Chang, "Basic Characteristics of Some Heatresisting Brazing Filler Materials", Welding $\mathscr{F} ., 1956,35$, (9), 431s-443s; "Further Evaluation of $\mathrm{Ni}-\mathrm{Cr}-\mathrm{B}$ and Au-18 Ni Brazing Alloys", Ibid., 1958, 37, (12), 535s-542s

5 M. H. Sloboda, "Design and Strength of Brazed Joints", Welding \& Metal Fab., 1961, 29, (7), 291-296

$6 \mathrm{~J}$. Kolbus and W. Hauch, "Beitrag zum Verhalten von Lötverbindungen aus Hochtamperaturloten auf Edelmetallbasis an hochwarmfesten Werkstoffen bei Zeitstands-Belastungen bis 1000 Stunden und Temperaturen bis zu 800 Grad C", Metall, 1969, 23, (10), 994-1002

7 Johnson Matthey, British Patent Application 39805/68

8 S. J. Whalen, "Aerospace Brazing", Welding Eng., 1968, 53, (3), 62-63

9 F. X. De Carlo, "Brazing Gives Apollo a Lift", $A m$. Machinist, 1967, 111, (15, July 17th), 84-87

\section{Gold in Electronic Engineering}

\section{THE INTER-NEPCON CONFERENGE AND EXHIBITION}

World consumption of gold in the electronics industry is now around 100 tons a year and is rising. This usage is, of course, scattered throughout many hundreds of companies operating in this rapidly growing field, but an unusual opportunity to appreciate the major importance of gold in both European and American techniques of electronic circuit design and production was presented at the "Inter-Nepcon 70 " held at Brighton in October. This combination of conference and exhibition, organised by the American journal Electronic Packaging and Production Magazine, attracted over thirteen thousand engineers and more than three hundred exhibitors.

The conspicuous role of gold, both in the papers presented and in the exhibits on view, concerned two distinct groups of components, the many types of contacts and connectors on the one hand and thick film circuits on the other. Increasing requirements of yield, reliability, and long life, combined with the smaller contact pressures available in miniaturised components, have led to the widespread use of gold as a contact material. Electroplating provides the answer in a great number of cases, and electrolytes of many kinds are available to provide high purity or alloyed gold deposits of good ductility and low porosity for contacts, edge connectors for printed circuit boards, semi-conductor devices and other electronic assemblies. In addition to conventional methods of electroplating, the use of continuously or selectively gold plated base metal strip from which parts can readily be produced is clearly becoming of importance. For more critical applications, metallurgically bonded gold inlays in base metal strip can similarly be formed into contacts or connectors. All these products were well represented in the exhibition, while a number of papers dealt with the problems of achieving operational reliability in goldsurfaced contacts and connectors when devices are so small that only very low contact pressures are available.

In the production of integrated and hybrid thick film circuits the individual components are produced by screen printing and firing on to a ceramic substrate a preparation containing one or more of the noble metals dispersed with a powdered glaze or frit in an organic medium. A wide range of gold-bearing preparations of this type is now available from several manufacturers, and these, together with appropriate screen printing machines and specialised furnaces for carrying out the carefully controlled firing operations were exhibited, while a number of papers and open discussions at the conference dealt with considerations of the selection of these materials and their processing into finished circuits. 